\title{
Measurement of Succinylacetone Using HPLC- Tandem Mass Spectrometry and Establishment of a Cut-off Value
}

Sun Hee Jun ${ }^{1, \star}$, Jong Do Seo ${ }^{2, *}$, Kyunghoon Lee $^{1,2}$, and Junghan Song ${ }^{1,2}$

${ }^{1}$ Department of Laboratory Medicine, Seoul National University Bundang Hospital, Seongnam; ${ }^{2}$ Department of Laboratory Medicine, Seoul National University College of Medicine, Seoul, Korea

Corresponding author: Junghan Song

Department of Laboratory Medicine, Seoul National University Bundang Hospital, 82 Gumi-ro 173beon-gil, Bundanggu, Seongnam 13620, Korea Tel: +82-31-787-7691

Fax: +82-31-787-4015

E-mail: Songjhcp@snu.ac.kr

${ }^{\star}$ These authors contributed equally to this work.
Background: Newborn screening of tyrosinemia type 1 is important for identifying infants at risk for developing this disease before life-threatening symptoms occur. It is difficult to differentiate between tyrosinemia type 1 and transient neonatal tyrosinemia (TNT) by analyzing tyrosine alone. Thus, succinylacetone must be analyzed. In this study, we measured succinylacetone in dried blood spot (DBS) by HPLC-tandem mass spectrometry (HPLC-MS/ MS) and established cut-off values.

Methods: We used the hydrazine derivatization method to measure succinylacetone in 127 DBSs showing normal results in the newborn screening test and 93 DBSs showing increased tyrosine levels. We established cut-off values using the 99.9th percentile value or median +5 standard deviation value.

Results: Succinylacetone levels determined by our method were well-correlated with the results recommended by the Centers for Disease Control and Prevention for proficiency testing $(r=0.9968)$. The succinylacetone levels in normal newborn DBSs were significantly lower than those in DBSs with high tyrosine levels $(P<0.001)$. The cut-off values were calculated to be $1.3 \mu \mathrm{M}$ from the results of 127 normal DBS samples and $2.2 \mu \mathrm{M}$ from 220 DBSs, including in 93 newborns with TNT.

Conclusions: Measurement of succinylacetone in DBSs by HPLC-MS/MS is useful in individuals with increased tyrosine concentrations and can be used for rapid differential diagnosis of tyrosinemia when an appropriate cut-off value is established.

(J Lab Med Qual Assur 2018;40:149-154)

Key Words: Succinylacetone, Tyrosinemias, Tandem mass spectrometry

\section{서론}

타이로신혈증(tyrosinemia)은 타이로신 대사에 관여하 는 효소의 결핍에 의해 혈중 타이로신 농도가 정상보다 높 아지는 유전성대사질환으로 일시적 신생아 타이로신혈증 (transient neonatal tyrosinemia, TNT)과 제1형 타이로신 혈증(tyrosinemia type 1), 제2형 타이로신혈증(tyrosinemia type 2), 제3형 타이로신혈증(tyrosinemia type 3) 등 여
러 종류가 있다[1,2]. 이 중 제2과 제3형 타이로신혈증은 tyrosine aminotransferase과 4-hydroxyphenylpyruvate dioxygenase $(\mathrm{HPD})$ 가 각각 결핍되어 타이로신의 심한 증가 를 보이기 때문에 쉽게 감별이 가능하다[1,2]. TNT의 경우 신 생아의 HPD 효소가 미성숙하여 타이로신 대사속도가 늦어 지면서 타이로신 농도가 일시적으로 높아지는 경우인데, 이 때 타이로신 증가 정도는 심하지 않고 그 증가도 일시적으로 나타나므로 별도의 치료가 필요하지 않다. 그러나 제1형 타이 
로신혈증은 타이로신 대사에 관여하는 fumarylacetoacetate hydrolase 효소가 결핍이 되어 fumaric acetoacetic acid 가 fumaric acid와 acetoacetate로 분해되지 못하고 체내에 타이로신과 succinylacetone으로 축적되어 간과 신장의 손 상과 신경질환이나 저인산성구루병 등의 질환을 일으킨다 [1-3]. 제1형 타이로신혈증은 100,000 명당 1 명꼴로 발병하 는 매우 드문 질환으로 조기에 치료 하지 못하면 1세 이하 에 사망하는 심각한 선천성 대사질환이지만 2-(2-nitro-4trifluoromethylbenzoyl)-1,3-cyclohexanedione로 치료가 가 능하고 신생아시기에 치료를 시작하게 되면 더욱더 효과적이 라는 보고도 있어 타이로신혈증에서 이 질병의 조기 감별은 매우 중요하다 $[2,4,5]$. 그러나 타이로신 증가 정도가 크지 않 기 때문에 탠덤질량분석기 $(\mathrm{MS} / \mathrm{MS})$ 를 이용한 신생아선별검 사에서 TNT와의 감별이 쉽지 않다. 따라서 제 1 형 타이로신혈 증의 특이 지표자인 succinylacetone을 측정하여 이의 증가여 부를 함께 확인하여 감별하여야 한다[2,6-9]. 따라서 신생아 선별검사에서 타이로신이 정상보다 높게 나타나는 경우, 신생 아는 다시 병원에 내원하여 별도의 소변이나 혈액을 채취하여 succinylacetone의 증가 여부를 확인하기 위한 유기산검사 등 을 추가로 시행하였다 [6,7]. 하지만 그 검사결과를 확인하기 까지 2-3주일 정도 소요하게 되어 조기감별이 쉽지 않았다. 신 생아선별검사 후 타이로신 농도가 증가한 잔여 건조혈액반점 (dried blood spot, DBS)에서 succinylacetone을 직접 측정 하는 방법이 개발된 후로는 제 1 형 타이로신혈증의 조기감별 진단이 가능해졌으며, DBS를 이용한 succinylacetone의 측정 은 기존의 방법과 비교할 때 별도의 검체 채취를 필요로 하지 않고 빠른 결과확인이 가능한 이점을 가지고 있어서 경도 내 지 중등도의 타이로신 농도증가를 보이는 제 1 형 타이로신혈증 과 TNT의 감별진단에 유용하게 활용될 수 있다 $[2,8,9]$. 그러 나 우리나라 정상 신생아 및 TNT에서 타이로신 농도에 따른 succinylacetone의 농도분포에 대한 연구가 진행된 바 없다. 본 연구에서는 정상 신생아와 TNT가 의심되는 신생아를 대상 으로 HPLC-MS/MS를 이용하여 DBS에서 succinylacetone 을 측정함으로써 succinylacetone의 판정기준치(cut-off value)를 산정하고, 타이로신 농도에 따른 succinylacetone 분 포를 분석하고자 하였다.

\section{재료 및 방법}

\section{1. 검체}

분당서울대학교병원에서 출생 시 체중 및 임신주수가 정상 인 신생아를 대상으로 생후 3-5일 사이에 시행한 신생아선별
검사에서 타이로신이 $250 \mu \mathrm{mol} / \mathrm{L}$ 미만으로 정상결과를 보였 던 DBS 잔여검체를 대조군으로 수집하였다. TNT 환자군은 2009년 8월부터 2012년 4월까지 시행한 신생아선별검사에서 타이로신이 $250 \mu \mathrm{mol} / \mathrm{L}$ 이상으로 비정상소견을 보이고 임상 적 증상이 없으면서 추적검사에서 타이로신이 정상화되었던 93개의 DBS 잔여검체를 대상으로 수집하였다.

\section{2. 시약}

Succinylacetone, hydrazine monohydrate, formic acid, acetonitrile, ethanol, 증류수 등은 HPLC 등급으로 SigmaAldrich (St. Louis, MO, USA)와 J.T. Baker (Avantor Performance Materials; Center Valley, PA, USA)에서 구 매하여 사용하였다. 내부표준물질(internal standard, IS)은 ${ }^{13} \mathrm{C}_{5}$-succinylacetone (Cambridge Isotope Laboratories Inc., Tewksbury, MA, USA)의 제품을 사용하였다.

\section{Succinylacetone 측정}

Succinylacetone 보정물질과 정도관리물질은 시판되는 물 질이 없어 자가 제조하여 사용하였다. 보정물질은 전혈에 succinylacetone을 $0,0.63,1.58,3.16,4.74,6.32 \mu \mathrm{mol} / \mathrm{L}$ 가 되도록 첨가하여 잘 혼합한 후, 여과지(Whatman No 901; GE Healthcare Bioscience, Pittsburgh, PA, USA)에 100 $\mu \mathrm{L}$ 씩 분주하여 $\mathrm{DBS}$ 를 만들어 상온, 암실에서 충분히 말린 후 $-70^{\circ} \mathrm{C}$ 의 냉동고에 보관하여 사용하였다. 정도관리물질은 정상 신생아 검체로 제조한 DBS와 정상 검체에 $1.90 \mu \mathrm{mol} /$ $\mathrm{L}$ succinylacetone을 첨가하여 고농도로 제조한 $\mathrm{DBS}$ 를 각 각 저농도와 고농도 정도관리물질로 사용하였다. IS는 $80 \%$ acetonitrile로 $0.13 \mu \mathrm{mol} / \mathrm{L}$ 농도가 되게 제조하여 사용하였 다.

보정물질, 정도관리물질 및 신생아 $\mathrm{DBS}$ 검체에서 각각 3/16인치 디스크를 채취하여 96-well plate에 옮겼다. IS 용 액 $100 \mu \mathrm{L}$ 를 각 well에 넣고 교반기에서 5 분간 잘 혼합하였 다. $200 \mathrm{mmol} / \mathrm{L}$ 의 hydrazine monohydrate $1.5 \mu \mathrm{L}$ 를 다시 각 well에 넣어준 후 다시 5 분간 충분히 혼합하였다. 증발을 막기 위해 plate에 덮개 필름을 부착한 후 $60^{\circ} \mathrm{C}$ 에서 30 분간 succinylacetone의 유도체가 형성되도록 하였다. 유도화가 끝 난 용출액 $90 \mu \mathrm{L}$ 를 다른 96-well plate에 옮긴 후 질소가스하 에서 약 10 분간 완전히 건조하였다. 남아 있는 hydrazine을 완전히 없애기 위하여 $100 \mu \mathrm{L}$ 의 ethanol을 각 well에 넣고 다 시 질소가스하에서 완전히 건조하였다. 이 건조된 검체를 60 $\mu \mathrm{L}$ 의 80\% acetonitrile 용액으로 재부유한 후 HPLC-MS/MS 의 자동 검체 주입구에 장착하여 검사를 진행하였다. 
Sun Hee Jun et al Cut-off Value of Succinylacetone

HPLC는 AQUITY UPLC system (Waters, Watford, $\mathrm{UK})$ 에 BEH C18 컬럼 $(2.1 \times 50 \mathrm{~mm}, 1.7 \mu \mathrm{m}$; Waters $)$ 을 사 용하였고, 유속은 $0.2 \mathrm{~mL} / \mathrm{min}$, 분석시간 3 분, 이동상 $\mathrm{A}$ 는 $0.1 \%$ formic acid 를 포함한 acetonitrile, 이동상 $\mathrm{B}$ 는 $0.1 \%$ formic acid를 포함한 증류수를 사용하여 $\mathrm{A}$ 와 $\mathrm{B}$ 를 8:2의 비 율로 등용매로 진행하였다. Succinylactone 피크는 정체시간 0.65 (0.60-0.70)분에서 관찰되었다. 질량분석기는 Xevo $\mathrm{TQ}$ $\mathrm{MS}$ (Waters)를 사용하였고 전기분사이온화(electrospray ionization), 양이온 모드, multiple reaction monitoring (MRM) 조건에서 검사를 시행하였다. Succinylacetone과 IS 의 MRM transition $(\mathrm{m} / \mathrm{z}$ )은 $155.1 \longrightarrow 137$ 과 $160.1 \longrightarrow 142$ 를 각 각 이용하였다. Cone voltage와 collision energy는 각각 22 $\mathrm{V}$ 와 $10 \mathrm{eV}$ 로 하였다. 측정된 자료의 정량은 QuanLynx 4.0 (Waters) 소프트웨어 프로그램을 이용하였다. 정도관리물 질에 대하여 10 회 반복측정을 시행하여 확인한 검사 내 정밀 도는 고농도와 저농도 정도관리물질에 대하여 각각 $6.3 \%$, $13.6 \%$ 였고, 11 일간의 검사 간 정밀도는 고농도와 저농도 정 도관리물질에 대하여 각각 $11.0 \%, 13.3 \%$ 였다. 직선성 평가에 서는 0-6.32 $\mu \mathrm{mol} / \mathrm{L}$ 농도범위에서 기울기는 1.0372 , 절편은 $-0.1134, R^{2}=0.9979$ 로, succinylacetone 측정에 신뢰할 만한 결과를 보여 주었다.

\section{4. 미국 Centers for Disease Control and Prevention 정도 관리물질과의 상관성 평가}

현재 succinylacetone 정도관리 $\mathrm{DBS}$ 가 별도로 시판되지 않고 상관성을 평가할 비교방법도 없어, 미국 Centers for Disease Control and Prevention (CDC)에서 2011년도에 진 행한 succinylacetone 정도관리 DBS 검체 4종류(lot 25, 26, $27,28)$ 를 이용하여 본 연구에서 개발한 방법으로 각각의 검 체에 대하여 3 회 반복측정을 시행한 후 그 평균값과 $\mathrm{CDC}$ 에 서 권장한 결과범위 및 참여기관의 평균값과 비교하였으며, Deming Regression 분석을 실시하였다.

\section{5. 판정기준치 산정}

DBS succinylacetone 판정기준치는 정상 신생아 127 명과, TNT가 의심되는 93 명을 포함한 220 명 전체를 대상으로 각각 99.9퍼센타일 값과 중앙값 +5 standard deviation (SD) 값으 로 산정하였다.

\section{6. 통계처리}

통계분석은 Microsoft Excel 2013 (Microsoft Corp., Redmond, WA, USA), MedCalc ver. 14.12.0 (MedCalc
Software BVBA, Ostend, Belgium), CBstat5 ver. 5.1.2 (Kristian Linnet, Charlottenlund, Denmark) 프로그램을 사용하였다.

\section{결과}

2011년도에 미국 CDC에서 진행한 succinylacetone 정도관 리 DBS 4종류(lot $25,26,27,28)$ 에 대하여 3회 반복검사를 시행하였다(Table 1). 저농도인 lot 25에서는 권장범위보다 약 간 높은 결과를, 고농도에서는 전반적으로 약간 낮은 결과를 보였다. Deming Regression 분석에서 기울기는 0.8661 (95\% confidence interval [CI], 0.5029 to 1.2293), 절편은 0.0970 (95\% CI, -0.9794 to 1.1734)였고, 상관계수는 0.9965로 양 호한 상관관계를 나타내었다.

신생아선별검사에서 타이로신 농도가 정상결과를 보인 127 개 DBS의 succinylacetone 결과는 평균 $0.34 \mu \mathrm{mol} / \mathrm{L}$, 표준 편차 $0.22 \mu \mathrm{mol} / \mathrm{L}, 0-1.28 \mu \mathrm{mol} / \mathrm{L}$ 의 결과분포를 보였으며, 중앙값은 $0.31 \mu \mathrm{mol} / \mathrm{L}$, 사분위수 구간은 0.18-0.42 $\mu \mathrm{mol} / \mathrm{L}$ 였다. 또한 타이로신 농도가 정상보다 높았던 93개 DBS의 succinylacetone 결과는 평균 $0.77 \mu \mathrm{mol} / \mathrm{L}$, 표준편차 0.31 $\mu \mathrm{mol} / \mathrm{L}, 0.16-1.70 \mu \mathrm{mol} / \mathrm{L}$ 의 결과분포를 보였으며, 중앙값 은 $0.77 \mu \mathrm{mol} / \mathrm{L}$, 사분위수 구간은 0.56-0.96 $\mu \mathrm{mol} / \mathrm{L}$ 로, 정상 신생아 DBS의 succinylacetone보다 통계적으로 유의하게 높 은 결과분포를 보였다(T검정, $P<0.001$ ) (Fig. 1). 총 220개 $\mathrm{DBS}$ 의 succinylacetone 결과는 평균 $0.52 \mu \mathrm{mol} / \mathrm{L}$, 표준편차 $0.34 \mu \mathrm{mol} / \mathrm{L}, 0-1.70 \mu \mathrm{mol} / \mathrm{L}$ 의 결과분포를 보였으며, 중앙값 은 $0.45 \mu \mathrm{mol} / \mathrm{L}$, 사분위수 구간은 0.25-0.76 $\mu \mathrm{mol} / \mathrm{L}$ 였다.

127 개의 정상 DBS의 succinylacetone 농도를 대상으로 99.9 퍼센타일 값과 중앙값 $+5 \mathrm{SD}$ 값으로 산정한 판정 기준치 는 각각 $1.3 \mu \mathrm{mol} / \mathrm{L}$ 와 $1.4 \mu \mathrm{mol} / \mathrm{L}$ 였다. 타이로신이 증가되어

Table 1. Comparison of succinylacetone levels determined in the present study, CDC recommended values, and averages of participating laboratories in 2011 CDC proficiency testing for succinylacetone using dried blood spots

\begin{tabular}{cccc}
\hline $\begin{array}{c}\text { Survey } \\
\text { material } \\
\text { lots }\end{array}$ & $\begin{array}{c}\text { Results of } \\
\text { this study } \\
(\mu \mathrm{mol} / \mathrm{L})\end{array}$ & $\begin{array}{c}\text { CDC } \\
\text { recommended } \\
\text { ranges }(\mu \mathrm{mol} / \mathrm{L}) \\
(\text { mean })\end{array}$ & $\begin{array}{c}\text { Averages of } \\
\text { participating labs } \\
(\mu \mathrm{mol} / \mathrm{L})(\text { no. of } \\
\text { participants })\end{array}$ \\
\hline 25 & 0.15 & $0.10-0.14(0.12)$ & $0.66(231)$ \\
26 & 2.32 & $2.37-3.34(2.84)$ & $2.54(230)$ \\
27 & 4.93 & $4.34-5.81(5.05)$ & $4.37(237)$ \\
28 & 8.95 & $8.75-11.21(10.42)$ & $8.30(239)$ \\
\hline
\end{tabular}

Abbreviation: CDC, centers for disease control and prevention. 


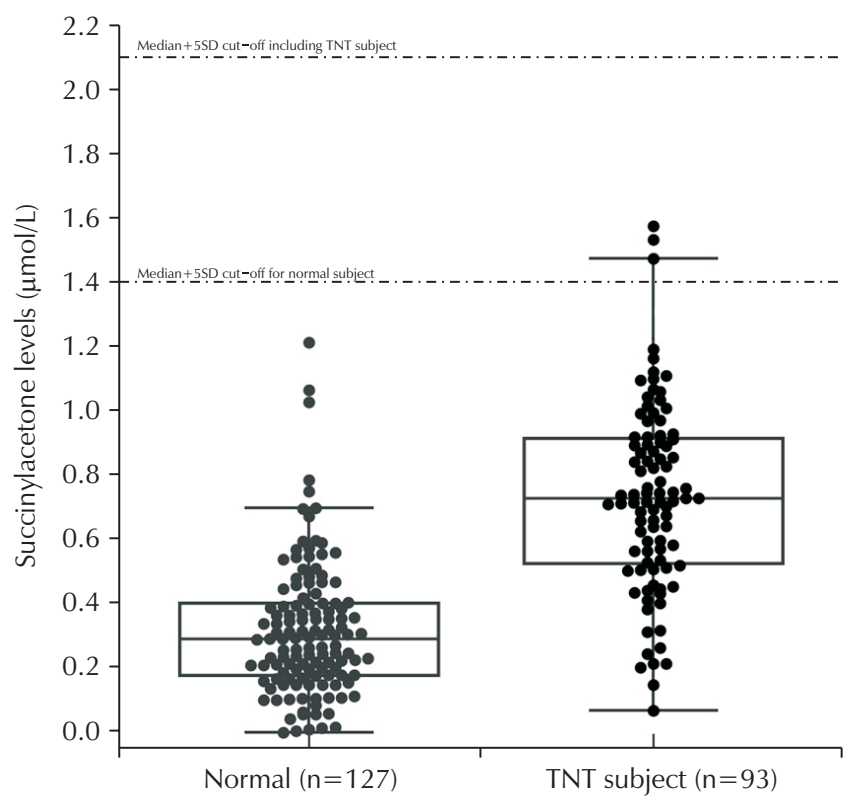

Fig. 1. Distribution of succinylacetone levels and median +5 standard deviation cut-off values in dried blood spot from normal newborns $(\mathrm{n}=127)$ and the newborns with suspected neonatal transient tyrosinemia (TNT) ( $\mathrm{n}=93)$.

있지만 TNT가 의심되는 93명을 포함하여 총 220 명을 대상으 로 99.9퍼센타일 값과 중앙값 $+5 \mathrm{SD}$ 값으로 산정한 판정기준 치는 각각 $1.7 \mu \mathrm{mol} / \mathrm{L}$ 와 $2.1 \mu \mathrm{mol} / \mathrm{L}$ 였다.

\section{고찰}

본 연구에서 개발한 방법으로 2011년 CDC 정도관리 DBS 의 succinylacetone을 측정한 결과를 살펴보면 lot 25 는 0.15 $\mu \mathrm{mol} / \mathrm{L}$ 였고 정도관리프로그램에 참여하였던 231기관들의 평균결과는 $0.66 \mu \mathrm{mol} / \mathrm{L}$ 였다. $\mathrm{CDC}$ 에서는 권장하는 범위는 $0.10-0.14 \mu \mathrm{mol} / \mathrm{L}$ 였다. Lot 28 결과는 $8.95 \mu \mathrm{mol} / \mathrm{L}$ 였고 정도 관리프로그램 참가기관의 평균은 $8.30 \mu \mathrm{mol} / \mathrm{L}, \mathrm{CDC}$ 에서는 권장하는 범위는 8.75-11.21 $\mu \mathrm{mol} / \mathrm{L}$ 였다. 본 연구에서 개발한 검사방법이 다른 참기기관보다 $\mathrm{CDC}$ 에서 권장한 결과범위에 더 근접하고 있는 것을 알 수 있다. 이는 대부분의 다른 기관에 서 스크리닝 목적으로 사용하기 위해 보정물질농도를 한 가지 만 사용하여 정량한 반면, 본 연구에서는 0에서 $6.32 \mu \mathrm{mol} / \mathrm{L}$ 까지 6 단계의 보정물질을 사용하였기 때문에 좀 더 정확한 것 으로 판단된다.

타이로신이 높았던 93명의 신생아 DBS는 모두 TNT인 경 우로 임상적 추적 및 신생아선별검사 당시와 동일한 질량분석
법 추적검사를 통하여 타이로신의 정상화를 관찰함으로써 확 인되었으며, TNT 환자에서 succinylacetone 수치가 127명 의 정상 DBS보다 통계적으로 의미 있게 높은 결과를 보인다 는 새로운 사실을 알게 되어 succinylacetone 농도를 바탕으로 $\mathrm{TNT}$ 를 감별 진단하는 것에 도움이 될 것으로 판단되었다.

임상검사의 참고치를 산정하는 방법은 여러 가지가 있으나 Clinical \& Laboratory Standards Institute (CLSI)에서 제 시하는 방법이 보편적으로 사용되고 있다[10]. 정상 집단에서 의 측정한 값이 정규분포를 하는 경우에는 $-2 \mathrm{SD}$ 와 $+2 \mathrm{SD}$ 를 참고범위로 산정하고, 정규분포를 하지 않는 경우에는 2.5 퍼센타일과 97.5퍼센타일 값을 참고범위로 산정하도록 권고 하고 있다. 그러나 유전성대사질환은 대부분 희귀질환이기 때 문에 이 질환에 대한 신생아 선별검사의 참고치를 CLSI 방법 으로 설정할 경우 너무 많은 위양성률이 생기는 문제점이 있 다. 탠덤질량분석기를 이용한 유전성대사질환에 대한 선별검 사의 판정기준치를 산정하는 가장 좋은 방법으로는 확진된 환 자를 대상으로 측정한 결과가 있을 경우 정상인과 환자를 확연 히 분별하는 값을 판정기준치를 산정하는 것이다. 그러나 대부 분의 유전성대사질환의 경우 확진된 환자 검체를 구하는 것이 어렵기 때문에 정상인을 대상으로 측정한 값에서 99.9퍼센타 일 또는 중앙값 $+5 \mathrm{SD}$ 값을 사용하기도 한다. La Marca 등[8] 은 중앙값 $+5 \mathrm{SD}$ 값으로 산정하여 $2.4 \mu \mathrm{mol} / \mathrm{L}$ 값을 제시하였 고, Metz 등[9]은 99.9퍼센타일 값으로 산정하여 $1.29 \mu \mathrm{mol} /$ $\mathrm{L}$ 값을 제시하였다. 최근의 종설에 의하면 보고자에 따라 1.29 부터 $10 \mu \mathrm{mol} / \mathrm{L}$ 까지 다양한 판정기준치를 사용하고 있고[11], 신빙도조사결과도 방법 간에 차이를 보이고 있는데, 이는 방법 간의 $\mathrm{DBS}$ 추출법의 차이, IS의 차이, 보정방법의 차이 때문에 기인한 것으로 추정하였다. 따라서 각 검사실마다 자체 판정기 준치 값을 설정하거나 검증하는 것이 필요하다.

본 연구에서 정상 신생아를 대상으로 중앙값 $+5 \mathrm{SD}$ 을 기준 으로 판정기준치를 산정한 값은 $1.4 \mu \mathrm{mol} / \mathrm{L}$ 였다. 이 판정기준 치를 사용할 경우 TNT로 의심되는 신생아의 $3.2 \%$ (3/93명) 에서 위양성을 보였다. 따라서 타이로신이 $250 \mu \mathrm{mol} / \mathrm{L}$ 이상 증가되어 $\mathrm{TNT}$ 가 의심되는 경우 TNT를 포함시켜 산정한 판 정기준치인 $2.1 \mu \mathrm{mol} / \mathrm{L}$ 를 사용하는 것이 바람직할 것으로 판 단되며, 이는 $1.29 \mu \mathrm{mol} / \mathrm{L}$ 의 판정기준치를 제안하였던 Metz 등[9]의 연구를 제외하면, 종설에서 파악된 2.0 부터 $10 \mu \mathrm{mol} /$ $\mathrm{L}$ 범위의 개별연구 판정기준치와도 부합하며 각각의 연구에 서 높은 민감도와 특이도, 양성예측도를 보였다[11].

본 연구의 제한점은 판정기준치 산정을 위한 대상수가 적었 고, 제 1 형 타이로신혈증 환자로 진단받은 $\mathrm{DBS}$ 검체가 없어 산정된 판정기준치에 대한 위양성, 위음성률 등 정확도 평가를 
Sun Hee Jun et al Cut-off Value of Succinylacetone

자체적으로 시행하지 못하고, 기존에 보고된 문헌과의 비교만 을 시행한 것이다. 앞으로 신생아선별검사가 의뢰된 $\mathrm{DBS}$ 에서 succinylacetone 측정을 계속 시행하여 정상군 및 비 정상군의 결과를 늘려나가 결과추이를 살펴보는 것이 필요하다.

신생아 선별검사에서 타이로신 농도가 정상보다 증가 하는 경우, 별도의 검체 채취 없이 잔여 $\mathrm{DBS}$ 검체에서 succinylacetone 측정을 시행함으로써 타이로신혈증의 대부분 을 차지하는 TNT와 제1형 타이로신혈증의 조기감별이 가능 하게 되었다. 이는 여러 가지 경제적 비용뿐만 아니라 결과를 받기까지 보호자들이 받는 스트레스나 걱정 등을 많이 해소하 게 될 것이다.

제1형 타이로신혈증을 조기감별진단하여 치료를 시작하게 되면 $90 \%$ 의 환자가 별다른 증상 없이 효과적으로 치료가 가 능하다. 따라서 succinylacetone 검사를 기존의 탠덤질량분석 기를 이용한 신생아선별검사와 함께 시행하고 적절한 판별기 준치를 사용한다면 제 1 형 타이로신혈증의 조기감별진단에 유 용할 것으로 생각된다.

\section{감사의 글}

본 연구는 분당서울대학교병원 일반연구비(02-2010-005) 지원에 의해 이루어졌다.

\section{REFERENCES}

1. Mitchell GA, Grompe M, Lambert M, Tanguay RM. Hypertyrosinemia. In: Scriver CR, Beaudet AL, Sly WS, Valle DV, editors. The metabolic and molecular bases of inherited disease. 8th ed. New York (NY): McGraw-Hill, 2001:1777-805.

2. Chinsky JM, Singh R, Ficicioglu C, van Karnebeek CDM, Grompe M, Mitchell G, et al. Diagnosis and treatment of tyrosinemia type I: a US and Canadian consensus group review and recommendations. Genet Med 2017;19. https://doi.org/10.1038/gim.2017.101.
3. Berger R, van Faassen H, Smith GP. Biochemical studies on the enzymatic deficiencies in hereditary tyrosinemia. Clin Chim Acta 1983;134:129-41.

4. Kvittingen EA. Tyrosinaemia type I: an update. J Inherit Metab Dis 1991;14:554-62.

5. Holme E, Lindstedt S. Nontransplant treatment of tyrosinemia. Clin Liver Dis 2000;4:805-14.

6. Grenier A, Lescault A, Laberge C, Gagne R, Mamer O. Detection of succinylacetone and the use of its measurement in mass screening for hereditary tyrosinemia. Clin Chim Acta 1982;123:93-9.

7. Jakobs C, Dorland L, Wikkerink B, Kok RM, de Jong AP, Wadman SK. Stable isotope dilution analysis of succinylacetone using electron capture negative ion mass fragmentography: an accurate approach to the pre- and neonatal diagnosis of hereditary tyrosinemia type I. Clin Chim Acta 1988;171:223-31.

8. La Marca G, Malvagia S, Pasquini E, Innocenti M, Fernandez MR, Donati MA, et al. The inclusion of succinylacetone as marker for tyrosinemia type I in expanded newborn screening programs. Rapid Commun Mass Spectrom 2008;22:812-8.

9. Metz TF, Mechtler TP, Merk M, Gottschalk A, Lukacin R, Herkner KR, et al. Evaluation of a novel, commercially available mass spectrometry kit for newborn screening including succinylacetone without hydrazine. Clin Chim Acta 2012;413:1259-64.

10. Clinical and Laboratory Standards Institute. Defining, establishing, and verifying reference intervals in the clinical laboratory: approved guideline: C28-A3C. 3rd ed. Wayne (PA): Clinical and Laboratory Standards Institute, 2010.

11. Stinton C, Geppert J, Freeman K, Clarke A, Johnson S, Fraser $\mathrm{H}$, et al. Newborn screening for Tyrosinemia type 1 using succinylacetone: a systematic review of test accuracy. Orphanet J Rare Dis 2017;12:48. 
Journal of LABORATORY MEDICINE and QUALITY ASSURANCE

Sun Hee Jun et al • Cut-off Value of Succinylacetone

탠덤질량분석기를 이용한 Succinylacetone 측정 및 판정기준치 산정

전선희 $^{1, *} \cdot$ 서종도 ${ }^{2, *} \cdot$ 이경훈 ${ }^{1,2} \cdot$ 송정한 $^{1,2}$

${ }^{1}$ 분당서울대학교병원 진단검사의학과, ${ }^{2}$ 서울대학교 의과대학 검사의학교실

배경: 타이로신혈증 중 타이로신의 증가가 심하지 않은 일시적 신생아 타이로신혈증과 제1형 타 이로신혈증은 타이로신 농도만으로는 감별이 어려워 추가적으로 succinylacetone 증가 유무를 확 인하여야 한다. 본 연구에서는 건조혈액반점(dried blood spot, DBS)에서 HPLC-탠덤질량분석기 (HPLC-MS/MS)를 이용하여 succinylacetone을 측정하였고 이에 대한 판정기준치를 산정하였다.

방법: DBS에서 추출한 succinylacetone은 hydrazine으로 유도체를 만든 후 HPLC-MS/MS를 이용 하여 측정하였다. Succinylacetone과 내부표준물질의 multiple reaction monitoring transition $(\mathrm{m} / \mathrm{z})$ 으로 $155.1 \rightarrow 137$ 과 $160.1 \rightarrow 142$ 을 각각 사용하였다. 신생아선별검사에서 정상의 결과를 보였던 127 개의 DBS와 타이로신이 높았던 93개 DBS에서 succinylacetone을 측정하였고, 그 결과를 이용 하여 판정기준치를 산정하였다.

결과: 신생아선별검사에서 정상의 결과를 보인 127 개 DBS의 succinylacetone 결과는 평균 0.34 $\mu \mathrm{mol} / \mathrm{L}(0-1.28 \mu \mathrm{mol} / \mathrm{L})$ 의 결과분포를 보였다. 또한 타이로신 농도가 정상보다 높았던 93 개 DBS 의 succinylacetone 결과는 평균 $0.77 \mu \mathrm{mol} / L(0.16-1.70 \mu \mathrm{mol} / L)$ 의 결과분포를 보여 정상 신생아 보다 통계적으로 유의하게 높은 결과분포를 보였다(T검정, $P<0.001$ ). 127 명의 정상 $\mathrm{DBS}$ 를 대상으 로 산정한 중앙값 +5 standard deviation (SD) 판정기준치는 $1.4 \mu \mathrm{mol} / \mathrm{L}$ 이었고, 타이로신이 증가되어 있지만 TNT가 의심되는 93명을 포함하여 총 220명을 대상으로 산정한 중앙값 $+5 S D$ 판정기준치는 $2.1 \mu \mathrm{mol} / \mathrm{L}$ 였다.

결론: DBS succinylacetone에 대한 적절한 판별기준치를 산정하여 이용한다면, 신생아선별검사에 서 타이로신 농도가 정상보다 높은 경우 succinylacetone의 측정은 타이로신혈증 조기감별진단에 대해 유용할 것으로 생각된다.

(J Lab Med Qual Assur 2018;40:149-154)

교신저자: 송정한

우)13620 경기도 성남시 분당구 구미로 173번길 82, 분당서울대학교병원 진단검사의학과

Tel: 031)787-7691. Fax: 031)787-4015, E-mail: songjhcp@snu.ac.kr

*These authors contributed equally to this work. 